PNL-SA-23600

\title{
TEMPEST: A COMPUTER CODE FOR THREE-DIMENSIONAL ANALYSIS OF TRANSIENT FLUID DYNAMICS
}

J. A. Fort

\section{DISCLAIMER}

\begin{abstract}
- This report was prepared as an account of work sponsored by an agency of the United States Government. Neither the United States Government nor any agency thereof, nor any of their employees, makes any warranty, express or implied, or assumes any legal liability or responsibility for the accuracy, completeness, or usefulness of any information, apparatus, product, or process disclosed, or represents that its use would not infringe privately owned rights. Reference herein to any specific commercial product, process, or service by trade name, trademark, manufacturer, or otherwise does not necessarily constitute or imply its endorsement, recommendation, or favoring by the United States Government or any agency thereof. The views and opinions of authors expressed herein do not necessarily state or reflect those of the United States Government or any agency thereof.
\end{abstract}

Handout

Prepared for

the U.S. Department of Energy

under Contract DE-AC06-76RLO 1830

Pacific Northwest Laboratory

Richland, Washington 99352 


\section{DISCLAIMER}

This report was prepared as an account of work sponsored by an agency of the United States Government. Neither the United States Government nor any agency thereof, nor any of their employees, make any warranty, express or implied, or assumes any legal liability or responsibility for the accuracy, completeness, or usefulness of any information, apparatus, product, or process disclosed, or represents that its use would not infringe privately owned rights. Reference herein to any specific commercial product, process, or service by trade name, trademark, manufacturer, or otherwise does not necessarily constitute or imply its endorsement, recommendation, or favoring by the United States Government or any agency thereof. The views and opinions of authors expressed herein do not necessarily state or reflect those of the United States Government or any agency thereof. 


\section{DISCLAIMER}

Portions of this document may be illegible in electronic image products. Images are produced from the best available original document. 
T'EMPEST stands for "Transient Energy Momentum and Pressure Equations Solutions in Three dimensions." It is a powerful tool for solving engineering problems in nuclear energy, waste processing, chemical processing, and environmental restoration because it analyzes and illustrates threedimensional time-dependent computational fluid dynamics and heat transfer analysis.

Developed by researchers at the U.S. Department of Energy's Pacific Northwest Laboratory. ${ }^{(n)}$ TEMPEST was first made available for business and industrial use in 1983. Since then, researchers at the Laboratory have been continuously upgrading the code to further extend its capabilities.

TEMPEST is a family of codes with two primary versions:

$\mathrm{N}$-Version. The configuration-controlled N-version, which is available to the public, can be used to analyze a broad range of coupled fluid dynamic and heat transfer systems in complex three-dimensional geometries. It includes a unique combination of code features and analysis capabilities, some of which are listed below.

T-Version. The developmental T-version is an important tool for investigators at the Pacific Northwest Laboratory, who use this version of TEMPEST in sponsored research for clients (it is not currently available to the public). It has all the capabilities of the $\mathrm{N}$-version; moreover, it can also be used to solve problems involving joule heating with ac/dc electric fields and joule heating models, compressible flows, marine hydrodynamics with free wave surfaces, and multi-constituent transport in curvilinear coordinates.

\section{Capabilities}

TEMPEST has.many useful features. Users select program controls to tailor the code for maximum analysis efficiency. Options include fluid dynamics, heat transfer, and species transport solutions. The T-version also includes the option for an electric field solution.

Pre- and post-processor programs allow the user to generate grids and visualize results. Pre-processor programs take advantage of TEMPEST T-version's generalized curvilinear coordinate capabilities by enabling the user to interactively fit regular computational grids to complex geometries. Post-processor programs allow the user to produce graphical images that aid in interpreting results of TEMPEST simula-

(a) Operated for the U.S. Department of Energy by Battelle Memorial Institute.

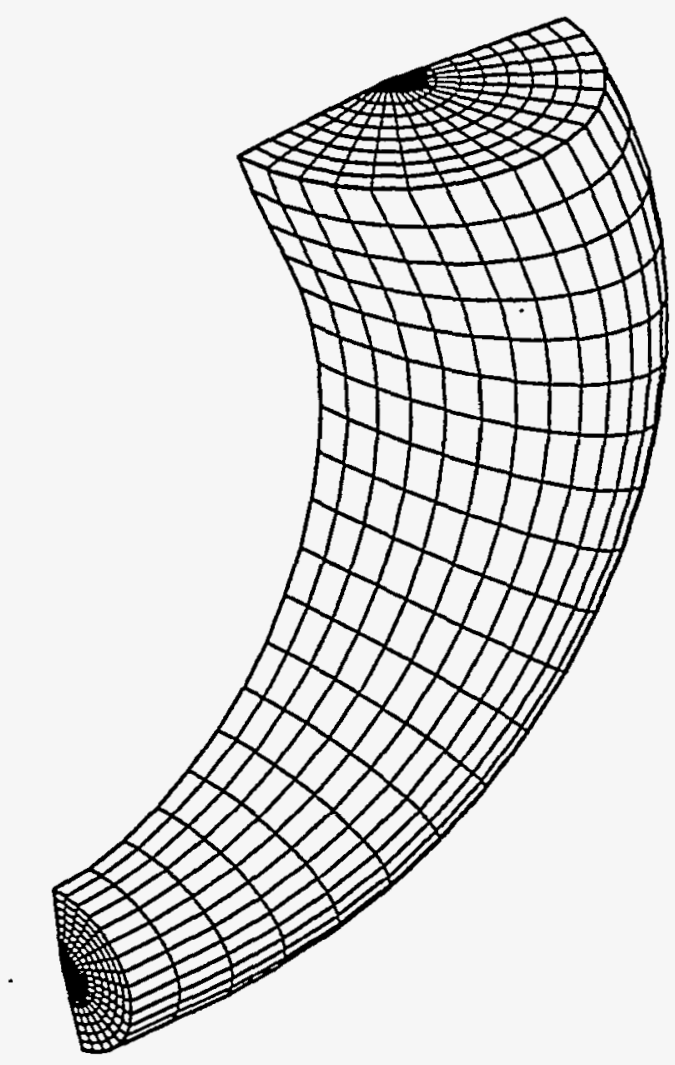

Complex geometrics can be simulated with the orthogonal curvilinear coordinate capability of TEMPEST. The grid shown here is for a pair of internal flow passages upstream of a mixingpump nozzle.

tions. Results are displayed using color PostScriptgenerating software packages, such as UNIRAS or DISSPLA, and the more general AVS (Application Visualization System) software. Examples of possible 2-D and 3-D visualizations include time sequence animations; vector, scalar iso-surface, and contour plots; and particle traces. The images may also be recorded on video tape.

Users can select modeling capabilities that meet the requirements of a specific analysis. The following list is representative. .

\section{- $\mathrm{N}$ - or T-Version}

- use rectangular or cylindrical coordinates in up to three dimensions

- specify material properties by user input or select from a built-in library for commonly used materials

- consider turbulence with a two-equation (k-e) model

- model settling solids and incompressible rising bubbles with concentration-dependent viscosity

- compute one-dimensional radiation across enclosures 
- place mass, momentum, energy, and turbulence production sources in computational regions

- specify thermal boundary conditions to fluid and solid regions

- model internal flow obstructions and multiple flow regions

- vary boundary and source conditions with time-dependent tables

- allow computed flow boundary conditions

- specify drag and heat transfer coefficients.

T-Version

- use generalized curvilinear coordinates

- model compressible flow at all flow speeds

- model AC/DC multi-phase multi-electrode systems

- model non-Newtonian fluid flow

- compute shallow water waves

- specify translating boundaries.

\section{Applications}

Its many features enable the TEMPEST to support a broad range of applications. In fact, the code has already proved useful in numerous areas:

- waste storage tank mixing phenomena sludge mobilization

forced mixing of particulates buoyancy-induced turnover/natural convection

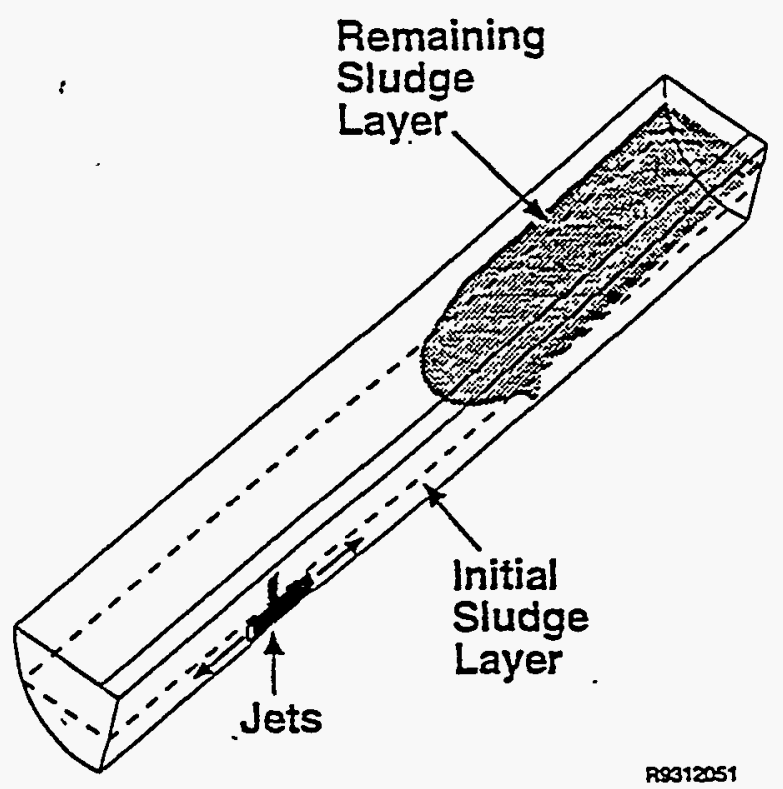

A9312051
- waste processing and storage

waste glass melter .

in-situ vitrification/heating

spent fuel and nuclear waste storage systems

- ventilation systems

room air and contaminant distribution

indoor air quality

exhaust plenum particulate flow

- energy conversion and storage

commercial hot water heaters

solar cavity receivers

solar-heated salt ponds

- marine hydrodynamies

thermal plume tracking

contaminant.(e.g., PCB) tracking

- nuclear reactors

light- and heavy-water cooled core and component design

liquid-metal cooled core and component design safety analysis.

\section{Numerical Algorithms}

TEMPEST's numerical algorithms are based on semi-implicit, finite-volume methods. Thus, the code can be used to solve time-dependent equations governing three-dimensional mass. momentum, and energy conservation for incompressible flows. Momentum equations are solved explicitly; continuity and pressure solutions are obtained implicitly. With the T-version, electric field equations are solved directly.

Solutions to scalar equations (energy, turbulence, constituents) are also obtained implicitly. With the T-version, the energy and electric field equations are solved over both fluid and solid regions. In both versions, hydrodynamic solutions are computed as transients with Courant-limited or viscosity-limited time steps.

\section{Development Status}

TEMPEST has been vectorized for use on Cray computers and adapted to run on UNIX-based workstations by Sun Microsystems, Hewlett-Packard. and IBM. Both also run on Macintosh workstations and VAXs. 
Moreover, TEMPEST is well documented. Published technical reports describe its mathematical models and numerical solution methods. User input, assessment and verification results, and many sample applications are also provided. The $\mathrm{N}$-version is maintained to quality assurance standards for reactor analysis applications.

\section{Availability and Assistance}

TEMPEST $N$-version is being released through the Energy Science and Technology Software Center at the Department of Energy's Oak Ridge National Laboratory. More than 70 copies of the $\mathrm{N}$-version have been provided to universities and industrial organizations.

Organizations needing support in applying either the $\mathrm{N}$ - or T-version of TEMPEST to a problem in fluid dynamics or heat transfer should contact one of the PNL staff members listed below. Assistance in areas such as training, problem analysis, and code modifications is available from our staff to individual clients or groups of clients who then share in the cost and benefits. Projects are tailored to specific needs using a selected combination of personnel, equipment and facilities.

\section{For answers to technical questions:}

L. Loren Eyler

phone: (509) 375-3740

email: 1l_eyler@pnl.gov

\section{On questions concerning code availability:}

Philiv C. Pulver

Software Products Manager.

phone: (509) 37.5-6787

fax: (509) 375-6499

Pacific Northwest Laboratory

P.O. Box 999

Richland, Washington 99352

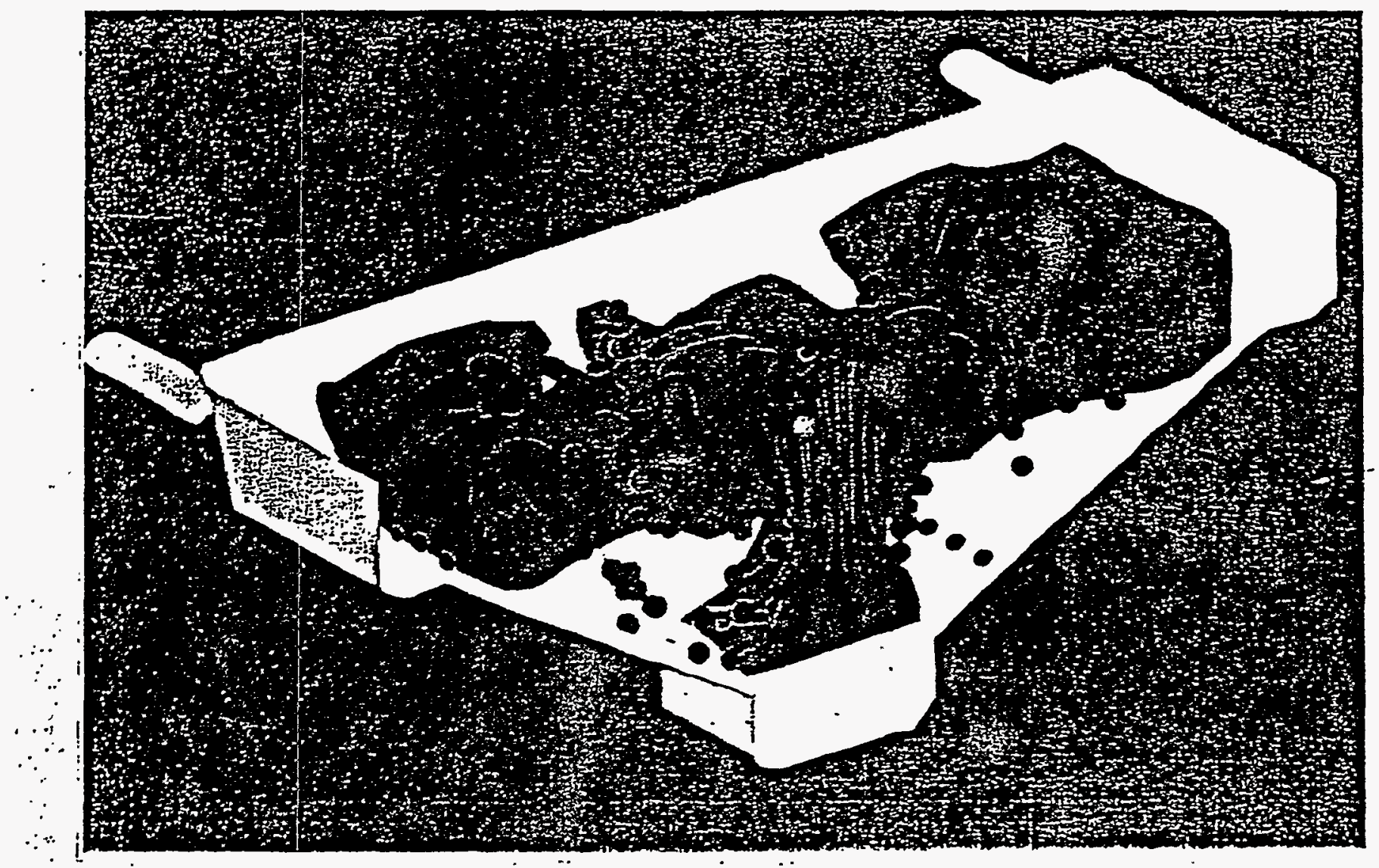

The behavior of waste glass inside an electric melter is simulated to investigate particulate buildup and operational performance. The computations take advantage of the fluid dynamics, heat transfer, and electric-field modeling features of TEMPEST. An isothermal surface is shown within the melt with particles tracing streamilines as visualized by Application Visualization System (AVS) post-processing. 


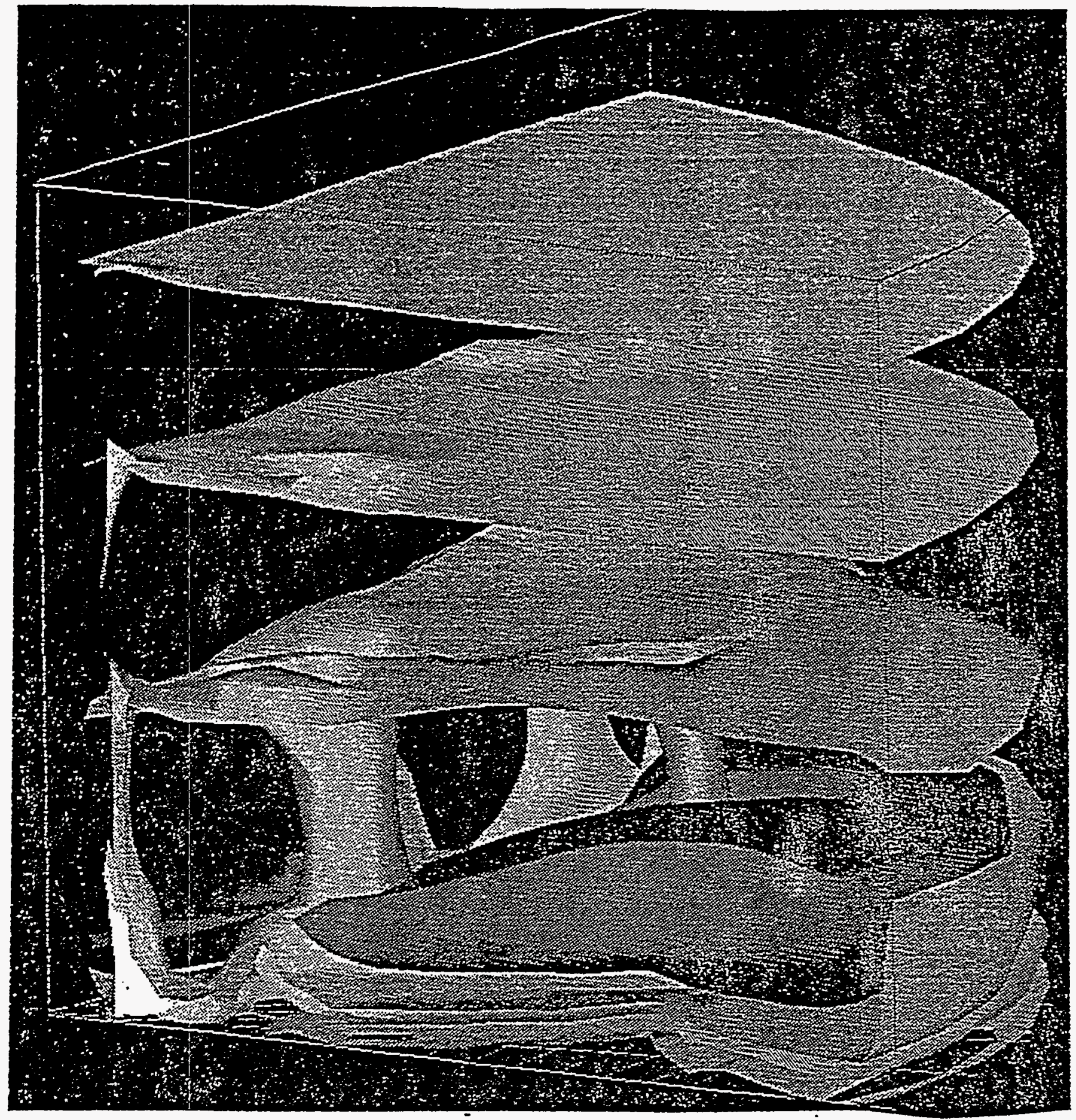

This TEMPEST simulation of a gas release from nuclear waste in a cylindrical tank shows a quarter section of the tank. Gas generated and trapped in a sludge layer at the tank bottom is released into the supernatant liquid layer by the start-up of a mixing jet. The isosurfaces represent constant values of the gas fraction. 